\title{
Quantum chemical studies of structures and spin Hamiltonian parameters of iron transferrin using isolated and embedded clusters models
}

\author{
LOKPATI MISHRA ${ }^{\mathrm{a}, \mathrm{b}}$ and MAHESH SUNDARARAJAN ${ }^{\mathrm{c}, *}$ \\ ${ }^{a}$ Radiation Safety and Systems Division, Bhabha Atomic Research Centre, Mumbai 400 085, India \\ ${ }^{\mathrm{b}}$ Homi Bhabha National Institute, Mumbai 400 094, India \\ ${ }^{\mathrm{c}}$ Theoretical Chemistry Section, Bhabha Atomic Research Centre, Mumbai 400 085, India \\ E-mail: smahesh@barc.gov.in
}

MS received 8 November 2018; revised 27 December 2018; accepted 31 December 2018; published online 4 February 2019

\begin{abstract}
Density functional theory (DFT) based calculations using large cluster models are used to elucidate the ground state electronic structure of iron bound transferrin. Explicit incorporation of second coordination amino acid residues and crystallographic water molecules anchors the active site. Our calculations clearly suggest that tyrosine amino acid (Tyr188) residue is bound to iron when the structures are optimized within the continuum solvation model. However, in the gas phase optimized structure, we note that Tyr188 is unbound to Fe (by more than $3 \AA$ ). The Mössbauer isomer shift $(\delta)$ and quadrupolar splitting $\left(\Delta \mathrm{E}_{\mathrm{q}}\right)$ of iron transferrin are in line with the experimental data only when Tyr188 is bound to Fe(III). Further, the computed oxygen hyperfine coupling constant value is very large $(-14.5 \mathrm{MHz})$ when bound to iron which can be verified through ${ }^{17} \mathrm{O}$ NMR experiments. We propose that Tyr188 is strongly bound to $\mathrm{Fe}(\mathrm{III})$ at physiological $\mathrm{pH}$, which needs to be protonated (acidic $\mathrm{pH}$ ) to weaken this bond, thus the metal release pathway can be possible only in acidic conditions.
\end{abstract}

Keywords. Transferrin; electronic structure; DFT; amino acid; modelling.

\section{Introduction}

Serum transferrin (sTf) is the protein that transports iron through the blood between sites of uptake, utilization, and storage. The major function of these proteins is to control the level of free iron in physiological fluids by binding and sequestering Fe(III) cations. ${ }^{1-3}$ The active site iron is octahedron geometry coordinated by two tyrosines (Tyr95, Tyr188), a histidine (His 249), an aspartate (Asp63) and an inorganic carbonate $\left(\mathrm{CO}_{3}{ }^{2-}\right)$ (Figure 1). ${ }^{4-6}$ Further, there are a number of amino acid residues in the second coordination shell such as arginine (Arg124), salt-bridged lysine (Lys206 and Lys296), threonine (Thr120) and several water molecules anchors the first coordination shell. It is now well-known that at physiological $\mathrm{pH}$ the $\mathrm{Fe}^{3+}$ binding strengths to the protein is very strong $\left(\mathrm{Ka}=10^{6} \mathrm{M}^{-1}\right)$. Only $30 \%$ of the sTf is occupied by $\mathrm{Fe}^{3+}$, whereas the remaining vacant sites can be accommodated by a variety of metal ions such as other $3 \mathrm{~d}$ transition metal ions (e.g., $\mathrm{Cu}^{2+}, \mathrm{Zn}^{2+}, \mathrm{Co}^{3+}$ and $\mathrm{Ni}^{3+}$ to name a few) and inner transition elements (e.g., $\left.\mathrm{Eu}^{3+}, \mathrm{Am}^{3+}, \mathrm{Cm}^{3+}, \mathrm{Th}^{4+}, \mathrm{Np}^{5+}, \mathrm{UO}_{2}^{2+}\right) .{ }^{7-20}$

A number of experimental studies have been carried out to understand the geometric and electronic structure and the ion release pathway of sTf. $4,5,7,21,22$ As the magnetic anisotropy is very small $\left(<0.5 \mathrm{~cm}^{-1}\right)$ due to half-filled $\mathrm{d}^{5}$ iron, ${ }^{23-27}$ the isomer shift and quadrupolar splitting of Fe derived from Mössbauer spectroscopy (MB) are often used to elucidate the electronic structure of the active site. ${ }^{28-30}$ As far as ion transmission pathways are concerned, several molecular dynamics simulations are carried out by varying the protonation state of the nearby amino acids such as salt bridged Lys, Tyr188, and carbonate. ${ }^{31}$ A number of computer studies are carried out on the geometric structures of iron-transferrin using small cluster models. ${ }^{10,31,32}$

\footnotetext{
*For correspondence

Electronic supplementary material: The online version of this article (https://doi.org/10.1007/s12039-019-1591-z) contains supplementary material, which is available to authorized users.
} 


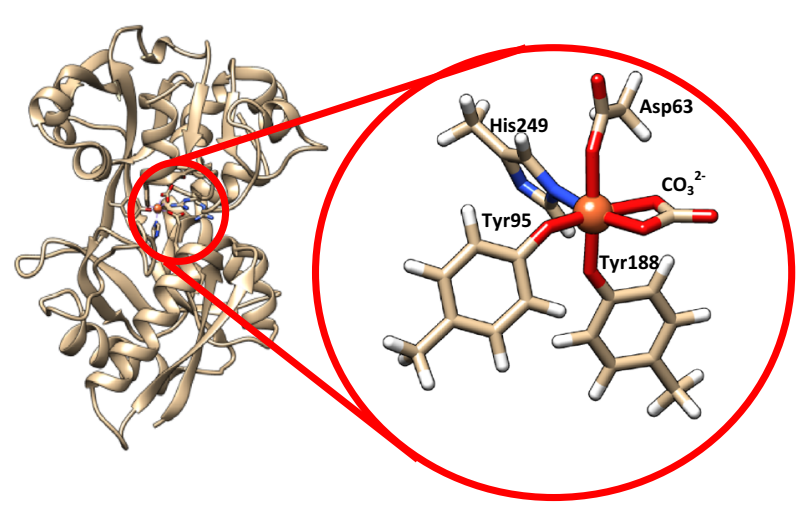

Figure 1. Active site structure of sTf.

Rinaldo and Field ${ }^{33}$ carried out the very first gas phase density functional theory (DFT) based calculations and suggested that salt bridged Lys-Lys could be vital for ion transmission due to the automatic proton transfer from Lys 296 to the bound Tyr 188 which weakens the Fe-Tyr188 interaction. However, recent molecular dynamics (MD) and QM/MM/MD simulations in physiological and in acidic $\mathrm{pH}$ suggest that Fe-Tyr188 interaction weakens only in acidic $\mathrm{pH} .{ }^{31-34}$

A plethora of spin Hamiltonian parameters $(\mathrm{SH})$ derived from MB spectroscopy and EPR spectroscopy are available which can directly reveal the electronic structure of iron sTf in physiological pH. ${ }^{15,23-26,28,29,35-38}$ Computing these $\mathrm{SH}$ parameters can directly reveal the coordination environment of $\mathrm{Fe}(\mathrm{III})$ in sTf which was never attempted before.

Thus, the question arises what is the geometric and electronic structure of iron bound sTf in physiological $\mathrm{pH}$ ? We have attempted to solve the important question through the computation of $\mathrm{SH}$ parameters derived from EPR and MB spectroscopy. ${ }^{39-43}$ Particularly, we propose that the oxygen $\left({ }^{17} \mathrm{O}\right)$ hyperfine coupling constant (HFCC) values of Tyr188 are very large $(>13 \mathrm{MHz})$ when bound to $\mathrm{Fe}(\mathrm{III})$ and very small $(<2 \mathrm{MHz})$ when it is unbound. These variations can be used as fingerprint values to distinguish the binding nature of Tyr 188 to $\mathrm{Fe}(\mathrm{III})$ ion.

\section{Experimental}

We have taken the $\mathrm{N}$ lobe structure of sTf for our computational study (PDB Code: 1A8E, $1.6 \AA$ resolution) ${ }^{5}$ In addition to the first coordination shell (Asp63, Tyr95, Tyr188, His249, and carbonate), we have incorporated the salt bridge (Lys206 and Lys296), hydrogen bonded residues such as Arg124 (to carbonate), Thr120 (to carbonate) and two crystallographic water molecules. It should be noted that the salt bridge (Lys296 and Lys206) is strongly hydrogen bonded to Tyr188 (Figure 2). In our calculations, we have truncated all amino acids between $\mathrm{C}_{\beta}-\mathrm{C}_{\alpha}$ positions. The $\mathrm{C}_{\alpha}$ carbons are fixed to crystallographic positions to mimic the steric effect of the protein. We have used large size cluster models which can be treated as an alternative to QM/MM models in line with our earlier studies and in the pioneering works by Siegbahn et al. ${ }^{44-46}$ We have earlier used large cluster models to understand the electronic structure of several metalloproteins which are comparable to QM/MM simulations. ${ }^{47-49}$

The choice of density functional is very crucial for the accurate prediction of geometry. In this area, both B3LYP and BP86 functionals are commonly applied to model metalloproteins. The structures are optimized in both vacuum (gas phase) and in protein dielectric $(\varepsilon=5)$ using dispersion corrected (D3BJ) BP86 functional ${ }^{47,48}$ in conjunction with TZVP ${ }^{49,50}$ basis set for all atoms. We have successfully used this functional to model the electronic structure of several iron and copper containing metalloproteins. ${ }^{39-42}$ We have also carried out additional calculations with neutral and anionic histidine's. The protein dielectric calculation is carried out using the COSMO continuum solvation model as implemented in TURBOMOLE 6.0. ${ }^{51}$

EPR and MB calculations are carried out at the DFT level using the B3LYP functional. ${ }^{52,53}$ The choice of using this functional is well-known that functionals containing HFexchange tend to predict the spin Hamiltonian parameters better than the pure functionals. Particularly for MB parameters, the standard deviation of B3LYP functional is smaller than the BP86 functional For these calculations, we used a $\mathrm{CP}(\mathrm{PPP})^{54}$ (for Fe) and TZVP (for all atoms) basis set. The technical details on the computation of SH parameters are discussed in detail in references. ${ }^{55,56}$ The isomer shift $(\delta)$ and the quadrupolar splitting $\left(\Delta \mathrm{E}_{\mathrm{q}}\right)$ are closely related to the electron density distribution of the iron nucleus.

To validate the computed SH parameters, we have computed the EPR parameters for copper transferrin, where the experimental data are known ${ }^{39-41}$ (ESI). Our predicted geometries and the g-tensor and hyperfine coupling constants (HFCC) of $\mathrm{Cu}$ and $\mathrm{N}$ (His249) are in excellent agreement with the experimental data. ${ }^{25}$

\section{Results and Discussion}

\subsection{Gas phase vs. embedded optimized geometries}

The optimized structures of sTf in isolated (gas phase) and in embedded models (optimized within the continuum solvation model) are very different (Figure 2 and Table 1). Significant geometric changes within the first coordination shell are observed within the two optimized structures. Particularly, a five-coordinated species is found in the optimized isolated model with a very long Fe-OTyr188 (more than $3 \AA$, Figure 2a). The longer Fe-OTyr 188 is attributed to the direct proton transfer from the neighboring salt bridge (Lys296) during optimization which leads to long Fe-OTyr188 bond and consequently, the Fe-OAsp63 bond (1.927 $\AA$ ) is 


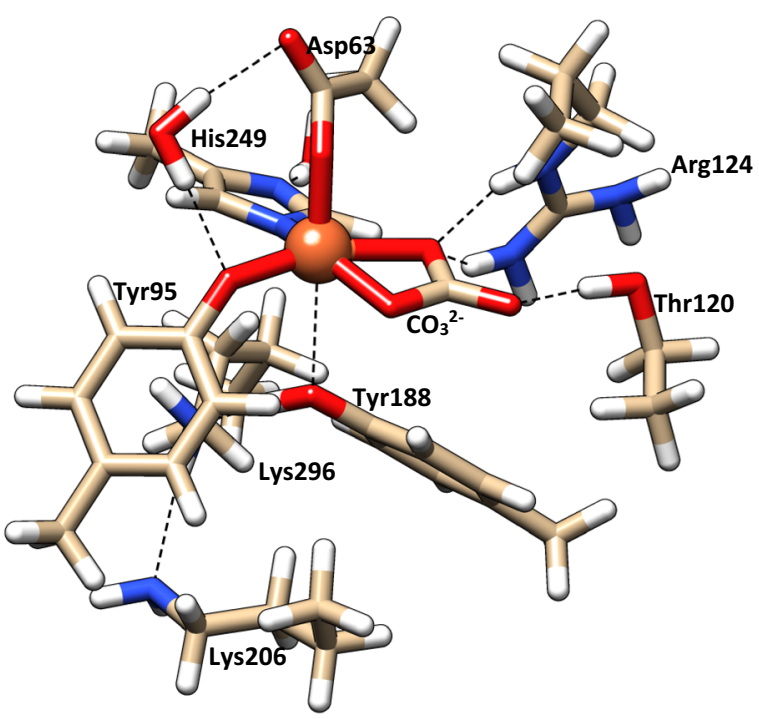

(a)

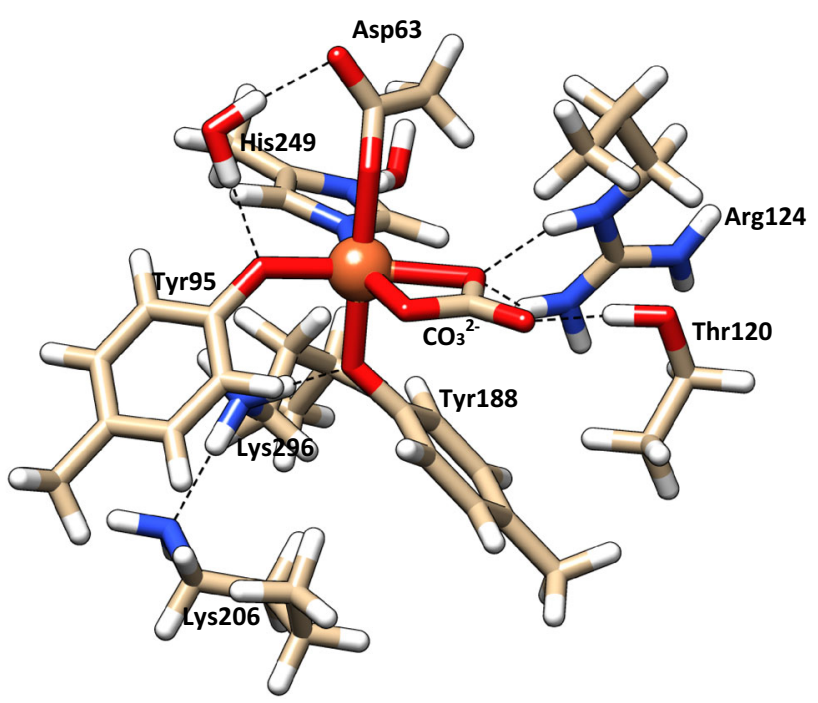

(b)

Figure 2. Optimized structures of (a) isolated and (b) embedded models.

Table 1. Optimized first coordination parameters (in $\AA$ ) around the iron center of sTf. ${ }^{\mathrm{a}}$

\begin{tabular}{lllllll}
\hline Models & $\mathrm{X}-\mathrm{O}_{\mathrm{Asp} 63}$ & $\mathrm{X}-\mathrm{O}_{\mathrm{Tyr} 95}$ & $\mathrm{X}-\mathrm{O}_{\text {Tyr188 }}$ & $\mathrm{X}-\mathrm{N}_{\mathrm{His} 249}$ & $\mathrm{X}-\mathrm{O}_{\mathrm{CO} 3}$ & $\mathrm{X}-\mathrm{O}{ }_{\mathrm{CO} 3}$ \\
\hline Isolated & 1.927 & 1.919 & 5.026 & 2.042 & 2.032 & 2.227 \\
Embedded & $2.043(2.032)$ & $2.110(1.957)$ & $2.078(2.058)$ & $2.110(2.194)$ & $2.072(2.035)$ & $2.212(2.197)$ \\
$\mathrm{X}$-ray & 2.02 & 1.99 & 1.90 & 2.10 & 2.06 & 2.24 \\
\hline
\end{tabular}

${ }^{a}$ Values given in the parenthesis are for an optimized embedded structure with neutral His249.

shortened. These geometric variations are also observed in the gas phase geometry optimizations of Rinaldo and Field. ${ }^{33}$ Further, the carbonate is asymmetrically bound to $\mathrm{Fe}$ (III) (2.032 to $2.227 \AA$ ) due to strong hydrogen bonding from Arg124 and Thr120 (Figure 2). We note that one water molecule is anchoring Tyr95 and Asp63 through a hydrogen bond, whereas the second water molecule is hydrogen bonded to anionic His249 ( $\delta$ or $\varepsilon$ ).

However, in the optimized embedded model, we find that Tyr188 is strongly bound to Fe(III) $(2.078 \AA$ ) and the proton is strongly intact with Lys296. Further, there is no proton transfer from salt bridged Lys 296 to Tyr 188 (1.663 $\AA$ ) which lead to conclude the hexacoordinated $\mathrm{Fe}(\mathrm{III})$ active site geometry. We find that even if we start with Tyr188 as protonated, we find that the proton simultaneously transferred back to Lys296 which is $\sim 9 \mathrm{kcal} \mathrm{mol}^{-1}$ lower in energy than when Tyr188 being protonated. These variations are consistent with the recent MD simulations study of Mujika et al., ${ }^{31}$ where they have suggested that only at low $\mathrm{pH}$, the metal release is possible. Finally, the Fe-OAsp63 bond length in the embedded model is elongated as compared to the isolated model by $0.12 \AA$. The other Fe-ligand bond lengths in the embedded and isolated models are very similar (Table 1). Further, we have also considered neutral His 249 which weaken the $\mathrm{Fe}-\mathrm{N}$ bond and alters the geometry significantly. Optimized first coordination parameters (in $\AA$ ) are given in brackets for an embedded structure with neutral His249. Indeed, Rinaldo et al., reported that His249 should be protonated. ${ }^{33}$ Other protonation sites such as Asp63 are beyond the scope of the work as we are focused only on physiological $\mathrm{pH}$.

Within the two clusters, we find that the embedded model (CPCM-B3LYP/TZVP//CPCM-BP86//TZVP) is more stable than the isolated cluster (CPCM-B3LYP/ TZVP//BP86//TZVP) by $6.97 \mathrm{kcal} \mathrm{mol}^{-1}$.

\subsection{MB and EPR spin Hamiltonian parameters}

We have computed the isomer shift $(\delta)$, quadrupolar splitting $\left(\Delta \mathrm{E}_{\mathrm{q}}\right)$ and $\mathrm{HFCC}$ of the coordinating ligands $\left({ }^{14} \mathrm{~N}\right.$ and $\left.{ }^{17} \mathrm{O}\right)$ of both optimized structures. The trivalent oxidation state of iron is a high spin state $\left({ }^{6} \mathrm{~A}_{1 \mathrm{~g}}\right)$ with half-filled d-orbitals. The computed spin Hamiltonian parameters using B3LYP functional for both isolated and embedded models are compared with experimental data (Table 2). We have also computed the SH parameters for the embedded cluster with neutral His 249 as well. 
Table 2. Computed MB (isomer shift $(\delta)$, quadrupolar splitting $\left.\left(\Delta \mathrm{E}_{\mathrm{q}}\right)\left(\mathrm{mm} \mathrm{s}^{-1}\right)\right)$ and superhyperfine coupling constants $\left(\mathrm{A}_{\text {iso }}, \mathrm{MHz}\right)$.

\begin{tabular}{lccccccccc}
\hline Models & $\delta$ & $\Delta \mathrm{E}_{\mathrm{q}}$ & ${ }^{\mathrm{Fe}} \mathrm{A}_{\text {iso }}$ & ${ }^{\mathrm{OAsp63}} \mathrm{A}_{\text {iso }}$ & ${ }^{\mathrm{OTyr} 95} \mathrm{~A}_{\text {iso }}$ & ${ }^{\mathrm{OTyr} 188} \mathrm{~A}_{\text {iso }}$ & ${ }^{\mathrm{NH} 249} \mathrm{~A}_{\text {iso }}$ & ${ }^{\mathrm{O} 1 \mathrm{CO} 3} \mathrm{~A}_{\text {iso }}$ & ${ }^{\mathrm{O} 2 \mathrm{CO} 3} \mathrm{~A}_{\text {iso }}$ \\
\hline Isolated & 0.478 & $1.241(1.145)$ & -17.0 & -17.3 & -15.2 & -1.5 & -8.3 & -7.9 & -7.7 \\
Embedded & 0.519 & $-0.578(-0.587)$ & -18.5 & -14.0 & -15.3 & -14.5 & -8.2 & -7.7 & -7.3 \\
Expt $^{30}$ & 0.38 & 0.75 & & & & & & & \\
\hline
\end{tabular}

The computed $\delta$ of both isolated $\left(0.478 \mathrm{~mm} \mathrm{~s}^{-1}\right)$ and embedded $\left(0.519 \mathrm{~mm} \mathrm{~s}^{-1}\right)$ models are in agreement with the experimental value $\left(0.38 \mathrm{~mm} \mathrm{~s}^{-1}\right)$ which is characteristic of high spin ferric species. However, the computed $\Delta \mathrm{E}_{\mathrm{q}}$ is very different for the two species. It should be noted that for high spin ferric systems, the $\Delta \mathrm{E}_{\mathrm{q}}$ should be minimal due to the absence of an electric field gradient. Between the two models, we find that $\Delta \mathrm{E}_{\mathrm{q}}$ is very large $\left(1.241 \mathrm{~mm} \mathrm{~s}^{-1}\right)$ for the isolated model, whereas for the embedded model this value is small $\left(-0.578 \mathrm{~mm} \mathrm{~s}^{-1}\right)$ and in line with experimental value $\left(0.75 \mathrm{~mm} \mathrm{~s}^{-1}\right)$. The major component in the $\Delta \mathrm{E}_{\mathrm{q}}$, is the electric field gradient which may be positive or negative. This depends on the type of asymmetry of the electronic charge distribution. These variations are perhaps due to large geometric variations in the isolated model (pentacoordinated iron) as compared to the embedded model (hexa-coordinated iron) which will be more prominently reflected in the HFCC of the ligands.

To our knowledge, the HFCC parameters derived from EPR spectroscopy in both experiment and in theory of native sTf was never measured or computed before. However, some insights on $\mathrm{Cu}$ bound sTf are known at least experimentally. ${ }^{25}$ To gauge our computational protocol, we have computed the EPR SH parameters of $\mathrm{Cu}$-sTf using the embedded model as described for FesTf. The optimized structural parameters and geometry are shown in Table S1 and Figure S1 (Supplementary Information). The Cu-OTyr188 is found to be weak in both X-ray $(\sim 2.8 \AA)$ and in optimized structure $(\sim 3.2 \AA)$ which is expected due to the Jahn-Teller nature of $\mathrm{Cu}$ (II) ion. ${ }^{43}$

An axial type g-tensor is predicted in our calculations $\left(\mathrm{g}^{\|}=2.225\right.$ and $\left.\mathrm{g}^{\perp}=2.071\right)$ in line with the experimental estimates of $\left(\mathrm{g}^{\|}=2.312\right.$ and $\left.\mathrm{g}^{\perp}=2.062\right)$. $^{7,15,36-38,57}$ It is now well-known that metal HFCC is very hard to predict due to the limitations of DFT itself. Nevertheless, we have corrected the $\mathrm{Cu}$ HFCC as discussed in the detailed investigation of Sinnecker and Neese. ${ }^{58}$ Our predicted Cu HFCC is now in excellent agreement with the experimental data with $10 \mathrm{MHz}$ which shows the reliability of our computational tool employed here even for challenging biomolecules.
As far as Fe-sTf are concerned, the computed HFCC of the directly bound amino acid ligands to the $\mathrm{Fe}(\mathrm{III})$ center is shown in Table 2. For both isolated and embedded models, the ${ }^{17} \mathrm{O}$ HFCC of carbonates $(\sim-7$ to $8 \mathrm{MHz}), \operatorname{Tyr} 95(\sim-15 \mathrm{MHz})$ and ${ }^{14} \mathrm{~N}$ of His249 $(\sim-8.2 \mathrm{MHz})$ are very similar. However, the computed HFCC of ${ }^{17} \mathrm{O}$ Tyr188 in the isolated model is very small $(-1.5 \mathrm{MHz})$ due to very long Fe-OTyr188 (more than $3 \AA$ ) thus the oxygen interaction with high spin $\mathrm{Fe}(\mathrm{III})$ is rather weak. However, the Fe-OTyr188 bond is very strong $(\sim 2.1 \AA)$ in the embedded model which lead to very large HFCC $(-14.5 \mathrm{MHz})$ due to stronger Fe-OTyr188 interaction. Conversely, ${ }^{17} \mathrm{O}$ HFCC of Asp65 in the embedded model is smaller $(-14.0 \mathrm{MHz})$ as compared to the isolated model $(-17.3 \mathrm{MHz})$. These variations are due to stronger Fe-OAsp bond in the isolated model $(\sim 1.9 \AA)$, whereas in the embedded model this distance is slightly longer $(\sim 2.1 \AA)$. These variations in super-HFCC of oxygens can be estimated through high field EPR and NMR studies. ${ }^{59-62}$

The quantum chemical study presented here provide valuable insights to understand the electronic structure of iron-transferrin at physiological $\mathrm{pH}$. Incorrect modeling such as neglecting the second coordination aminoacid residues, solvation and explicit incorporation of water molecules can lead to biased conclusions is clear from our study. Further, from a biochemistry perspective, our study suggests that at physiological $\mathrm{pH}$, $\mathrm{Fe}^{3+}$ remain strongly bound and an external perturbation such as lowering of $\mathrm{pH}$. In acidic conditions, Ty 188 aminoacid will be protonated and can weaken its interaction with $\mathrm{Fe}^{3+}$, thus releasing the iron.

\section{Conclusions}

In this paper, we have carried out electronic structure calculations to understand the debatable geometric structure of Fe-sTf. We find that the use of gas phase geometry optimization predicts a wrong pentacoordinated geometric structure and thus an incorrect electronic structure, whereas the geometry predicted within the continuum solvation model is hexacoordinate. We predict that Fe in sTf is hexa-coordinated with 
a bound OTyr188 at physiological pH. Our computed MB parameters are in line with the experimental data only when OTyr188 is bound to Fe. Further, ${ }^{17} \mathrm{O}$ HFCC of Tyr188 is very large $(-14.5 \mathrm{MHz})$ when bound to $\mathrm{Fe}$ as compared to unbound state $(-1.5 \mathrm{MHz})$ which can be measured with paramagnetic NMR experiments.

\section{Acknowledgements}

Lokpati Mishra acknowledges the continuous encouragement and guidance by Dr. I. S. Singh \& Dr. P. D. Sawant, IDS, RSSD and Dr. K.S. Pradeepkumar, Head, RSSD, \& Associate Director, HS\&EG, BARC. MS thank aggra systems for computational facilities.

\section{References}

1. Sun H, Li H and Sadler P J 1999 Transferrin as a Metal Ion Mediator Chem. Rev. 992817

2. Cook J D, Skikne B S and Baynes R D 1993 Serum Transferrin Receptor Annu. Rev. Med. 4463

3. Crichton R R and Charloteaux-Wauters M 1987 Iron transport and storage Eur. J. Biochem. 164485

4. Mason A B, Halbrooks P J, James N G, Connolly S A, Larouche J R, Smith V C, MacGillivray R T A and Chasteen N D 2005 Mutational Analysis of C-Lobe Ligands of Human Serum Transferrin: Insights into the Mechanism of Iron Release Biochemistry 448013

5. MacGillivray R T A, Moore S A, Chen J, Anderson B F, Baker H, Luo Y, Bewley M, Smith C A, Murphy M E P, Wang Y et al. 1998 Two High-Resolution Crystal Structures of the Recombinant N-Lobe of Human Transferrin Reveal a Structural Change Implicated in Iron Release Biochemistry 377919

6. Princiotto J V and Zapolski E J 1975 Difference between the two iron-binding sites of transferrin Nature 25587

7. El Hage Chahine J-M, Hémadi M and Ha-Duong N-T 2012 Uptake and release of metal ions by transferrin and interaction with receptor 1 Biochim. Biophys. Acta $\mathbf{1 8 2 0}$ 334

8. Hémadi M, Ha-Duong N-T and El Hage Chahine JM 2011 Can Uranium Be Transported by the IronAcquisition Pathway? Ur Uptake by Transferrin J. Phys. Chem. B 1154206

9. Jeanson A, Ferrand M, Funke H, Hennig C, Moisy P, Solari P L, Vidaud C and Den Auwer C 2010 The Role of Transferrin in Actinide(IV) Uptake: Comparison with Iron(III) Chem. Eur. J. 161378

10. Benavides-Garcia M G and Balasubramanian K 2009 Structural Insights into the Binding of Uranyl with Human Serum Protein Apotransferrin Structure and Spectra of Protein-Uranyl Interactions Chem. Res. Toxicol. 221613

11. Vidaud C, Gourion-Arsiquaud S, Rollin-Genetet F, Torne-Celer C, Plantevin S, Pible O, Berthomieu C and Quéméneur E 2007 Structural Consequences of Binding of $\mathrm{UO}_{2}^{2+}$ to Apotransferrin: Can This Protein Account for Entry of Uranium into Human Cells? Biochemistry 462215
12. Kay C W M, Mkami H, Cammack R and Evans R W 2007 Pulsed ELDOR Determination of the Intramolecular Distance between the Metal Binding Sites in Dicupric Human Serum Transferrin and Lactoferrin J. Am. Chem. Soc. 1294868

13. Tinoco A D and Valentine A M 2005 Ti(IV) Binds to Human Serum Transferrin More Tightly Than Does Fe(III) J. Am. Chem. Soc. 12711218

14. Zak O and Aisen P 1988 Spectroscopic and thermodynamic studies on the binding of gadolinium(III) to human serum transferrin Biochemistry 271075

15. Gaber B P, Miskowski V and Spiro T G 1974 Resonance Raman scattering from iron(III)- and copper(II)transferrin and an iron(III) model compound. Spectroscopic interpretation of the transferrin binding site J. Am. Chem. Soc. 966868

16. Aisen P, Aasa R and Redfield A G 1969 The Chromium, Manganese, and Cobalt Complexes of Transferrin J. Biol. Chem. 2444628

17. Sauge-Merle S, Lemaire D, Evans R W, Berthomieu C and Aupiais J 2017 Revisiting binding of plutonium to transferrin by CE-ICP-MS Dalton Trans. 461389

18. Abergel R J and Ansoborlo E 2016 Curious curium Nat. Chem. 8516

19. Bauer N, Frohlich D R and Panak P J 2014 Interaction of $\mathrm{Cm}$ (iii) and $\mathrm{Am}$ (iii) with human serum transferrin studied by time-resolved laser fluorescence and EXAFS spectroscopy Dalton Trans. 436689

20. Bauer N, Smith V C, MacGillivray R T A and Panak P J 2015 Complexation of $\mathrm{Cm}$ (iii) with the recombinant $\mathrm{N}$ lobe of human serum transferrin studied by time-resolved laser fluorescence spectroscopy (TRLFS) Dalton Trans. 441850

21. Steere A N, Miller B F, Roberts S E, Byrne S L, Chasteen N D, Smith V C, MacGillivray R T A and Mason A B 2012 Ionic Residues of Human Serum Transferrin Affect Binding to the Transferrin Receptor and Iron Release Biochemistry 51686

22. Borisenko G G, Kagan V E, Hsia C J C and Schor N F 2000 Interaction between 6-Hydroxydopamine and Transferrin: "Let My Iron Go" Biochemistry 393392

23. Mathies G, Gast P, Chasteen N D, Luck A N, Mason A B and Groenen E J J 2015 Exploring the Fe(III) binding sites of human serum transferrin with EPR at $275 \mathrm{GHz}$ J. Biol. Inorg. Chem. 20487

24. Gaffney B J 2009 EPR of Mononuclear Non-Heme Iron Proteins BT - High Resolution EPR: Applications to Metalloenzymes and Metals in Medicine (New York: Springer New York)

25. Seidel A, Bill E, Haggstrom L, Nordblad P and Kilar F 1994 Complementary Mössbauer and EPR Studies of Iron(III) in Diferric Human Serum Transferrin with Oxalate or Bicarbonate as Synergistic Anions Arch. Biochem. Biophys. 30852

26. Doctor K S, Gaffney B J, Alvarez G and Silverstone H J 1993 EPR spectroscopy of interdoublet transitions in high-spin iron: applications to transferrin oxalate J. Phys. Chem. 973028

27. Rottman G A, Doi K, Zak O, Aasa R and Aisen P 1989 Hyperfine interactions of iron-57 in human transferrin: an ENDOR spectroscopic study J. Am. Chem. Soc. 111 8613 
28. Tsang C P, Bogner L and Boyle A J F 1976 Further Mössbauer study of iron in human transferrin J. Chem. Phys. 654584

29. Tsang C P, Boyle A J F and Morgan E H 1973 Mössbauer spectroscopy of iron in human and rabbit transferrin Biochim. Biophys. Acta Protein Struct. 328 84

30. Spartalian K and Oosterhuis W T 1973 Mössbauer effect studies of transferrin J. Chem. Phys. 59617

31. Mujika J I, Escribano B, Akhmatskaya E, Ugalde J M and Lopez X 2012 Molecular Dynamics Simulations of Iron- and Aluminum-Loaded Serum Transferrin: Protonation of Tyr188 Is Necessary To Prompt Metal Release Biochemistry 517017

32. Rinaldo D and Field M J 2004 A Density Functional Theory Study of the Iron-Binding Site of Human Serum Transferrin Aust. J. Chem. 571219

33. Rinaldo D and Field M J 2003 A Computational Study of the Open and Closed Forms of the N-Lobe Human Serum Transferrin Apoprotein Biophys. J. 85 3485

34. Kumar R and Mauk A G 2012 Protonation and Anion Binding Control the Kinetics of Iron Release from Human Transferrin J. Phys. Chem. B 1163795

35. Gaffney B J, Eaton G R and Eaton S S 1998 Electron Spin Relaxation Rates for High-Spin Fe(III) in Iron Transferrin Carbonate and Iron Transferrin Oxalate J. Phys. Chem. B 1025536

36. Eaton S S, Dubach J, Eaton G R, Thurman G and Ambruso D R 1990 Electron spin echo envelope modulation evidence for carbonate binding to iron(III) and copper(II) transferrin and lactoferrin J. Biol. Chem. 265 7138

37. Zweier J L 1978 An electron paramagnetic resonance study of single site copper complexes of transferrin $J$. Biol. Chem. 2537616

38. Aasa R and Aisen P 1968 An Electron Paramagnetic Resonance Study of the Iron and Copper Complexes of Transferrin J. Biol. Chem. 2432399

39. Sundararajan M and Neese F 2015 Distal Histidine Modulates the Unusual O-Binding of Nitrite to Myoglobin: Evidence from the Quantum Chemical Analysis of EPR Parameters Inorg. Chem.

40. Sundararajan M and Neese F 2012 Detailed QM/MM study of the Electron Paramagnetic Resonance Parameters of Nitrosyl Myoglobin J. Chem. Theory Comput. 8 563

41. Lancaster K M, Zaballa M, Sproules S, Sundararajan M, DeBeer S, Richards J H, Vila A J, Neese F and Gray H B 2012 Outer-Sphere Contributions to the Electronic Structure of Type Zero Copper Proteins J. Am. Chem. Soc. 1348241

42. Periyasamy G, Sundararajan M, Hillier I H, Burton N A and McDouall J J W 2007 The binding of nitric oxide at the $\mathrm{Cu}(\mathrm{i})$ site of copper nitrite reductase and of inorganic models: DFT calculations of the energetics and EPR parameters of side-on and end-on structures Phys. Chem. Chem. Phys. 92498

43. Smith C A, Anderson B F, Baker H M and Baker E N 1992 Metal substitution in transferrins: the crystal structure of human copper-lactoferrin at 2.1ANG resolution Biochemistry 314527
44. Siegbahn P E M and Blomberg M R A 2000 TransitionMetal Systems in Biochemistry Studied by HighAccuracy Quantum Chemical Methods Chem. Rev. 100 421

45. Siegbahn P E M and Borowski T 2006 Modeling Enzymatic Reactions Involving Transition Metals Acc. Chem. Res. 39729

46. Siegbahn P E M and Himo F 2011 Siegbahn Per E M and Himo F 2011 The quantum chemical cluster approach for modeling enzyme reactions WIREs Comput. Mol. Sci. 1 323

47. Becke A D 1988 Density-functional exchange-energy approximation with correct asymptotic behavior Phys. Rev. A 383098

48. Perdew J P 1986 Density-functional approximation for the correlation energy of the inhomogeneous electron gas Phys. Rev. B 338822

49. Schäfer A, Horn H and Ahlrichs R 1992 Fully optimized contracted Gaussian basis sets for atoms $\mathrm{Li}$ to $\mathrm{Kr}$ J. Chem. Phys. 972571

50. Schäfer A, Huber C and Ahlrichs R 1994 Fully optimized contracted Gaussian basis sets of triple zeta valence quality for atoms Li to Kr J. Chem. Phys. 1005829

51. R. Ahlrichs e a. TURBOMOLE V6.0 2009, a development of University of Karlsruhe and Forschungszentrum Karlsruhe GmbH, 1989-2007, TURBOMOLE GmbH, since 2007; available from http://www.turbomole. com.(2011).

52. Lee C, Yang W and Parr R G 1988 Development of the Colle-Salvetti correlation-energy formula into a functional of the electron density Phys. Rev. B 37 785

53. Becke A D 1993 Density-functional thermochemistry. III. The role of exact exchange J. Chem. Phys. 98 5648

54. Neese F 2002 Prediction and interpretation of the 57Fe isomer shift in Mössbauer spectra by density functional theory Inorg. Chim. Acta 337181

55. Sinnecker S, Slep L D, Bill E and Neese F 2005 Performance of Nonrelativistic and Quasi-Relativistic Hybrid DFT for the Prediction of Electric and Magnetic Hyperfine Parameters in ${ }^{57} \mathrm{Fe}$ Mössbauer Spectra Inorg. Chem. 442245

56. Römelt M, Ye S and Neese F 2009 Calibration of Modern Density Functional Theory Methods for the Prediction of ${ }^{57} \mathrm{Fe}$ Mössbauer Isomer Shifts: Meta-GGA and DoubleHybrid Functionals Inorg. Chem. 48784

57. Froncisz W and Aisen P 1982 The EPR spectra of copper transferrin complexes at 2-4 GHZ Biochim. Biophys. Acta (BBA) Protein Struct. Mol. Enzymol. 700 55

58. Sinnecker S and Neese F 2006 QM/MM calculations with DFT for taking into account protein effects on the EPR and optical spectra of metalloproteins. Plastocyanin as a case study J. Comput. Chem. 27 1463

59. Astashkin A V, Neese F, Raitsimring A M, Cooney J J A, Bultman E and Enemark J H 2005 Pulsed EPR Investigations of Systems Modeling Molybdenum Enzymes: Hyperfine and Quadrupole Parameters of $\mathrm{Oxo}-{ }^{17} \mathrm{O}$ in $\left[\mathrm{Mo}^{17} \mathrm{O}(\mathrm{SPh})_{4}\right]^{-} \mathrm{J}$. Am. Chem. Soc. 127 16713 
60. Cox N, Pantazis D A, Neese F and Lubitz W 2013 Biological Water Oxidation Acc. Chem. Res. 46 1588

61. Cox N, Retegan M, Neese F, Pantazis D A, Boussac A and Lubitz W 2014 Electronic structure of the oxygenevolving complex in photosystem II prior to O-O bond formation Science $\mathbf{3 4 5} 804$
62. Lohmiller T, Krewald V, Navarro M P, Retegan M, Rapatskiy L, Nowaczyk M M, Boussac A, Neese F, Lubitz W, Pantazis D A and Cox N 2014 Structure, ligands and substrate coordination of the oxygen-evolving complex of photosystem II in the S2 state: a combined EPR and DFT study Phys. Chem. Chem. Phys. 16 11877 